Proceedings of the

International Geometry Center

Vol. 12 , no. 1 (2019) pp. $70-78$

Vol. 12, no. 1 (2019) pp. $70-78$

\title{
A Physics-Based Estimation of Mean Curvature Normal Vector for Triangulated Surfaces
}

\author{
Sudip Kumar Das, Mirza Cenanovic, Junfeng Zhang
}

\begin{abstract}
In this note, we derive an approximation for the mean curvature normal vector on vertices of triangulated surface meshes from the YoungLaplace equation and the force balance principle. We then demonstrate that the approximation expression from our physics-based derivation is equivalent to the discrete Laplace-Beltrami operator approach in the literature. This work, in addition to providing an alternative expression to calculate the mean curvature normal vector, can be further extended to other mesh structures, including non-triangular and heterogeneous meshes.
\end{abstract}

\begin{abstract}
Анотація. Оцінка норми і кривини для тріангульованої поверхні необхідна для багатьох обчислень і моделювання, таких як комп'ютерна графіка, зворотна розробка, аналіз медичних зображень і моделювання багатофазних потоків. Враховуючи те, що нормальний вектор і середня кривизна на гладкій поверхні можуть бути виражені оператором Лапласа-Бельтрамі з диференціальної геометрії, автори Desbrum та ін. інтегрували цей оператор над поверхнею управління навколо вершини триангульованої сітки і знайшли оцінки локального середнього вектора кривини. 3 того часу їх метод застосовується в таких областях як комп'ютерна графіка, штучний інтелект та біомедична інженерія.

В даній роботі ми пропонуємо новий підхід для оцінки середньої кривини та нормального вектора з суто фізичної точки зору. Метод складається з двох кроків. По-перше, згідно класичного рівняння Янга-Лапласа для поверхні розділу двох рідин, вузлова сила в вершині триангульованої поверхні пов'язана з середньою кривизною та поверхневим натягом межі рідини і направлена нормально до поверхні. По-друге, за допомогою механічного принципу балансу сил на триангульованій поверхні можна знайти прості формули для обчислення вузлових сил. Більш того, що апроксимаційні вирази для вузлових сил, отримані в даній роботі з фізичних міркувань, математично еквівалентні виразам отриманим Desbrum та інгими авторами за допомогою дискретного оператора Лапласа-Бельтрамі. 3 іншого боку, наш метод може бути поширений на
\end{abstract}

Keywords: Mean Curvature, Computer Graphics, Laplace-Beltrami Operator, Multiphase Flows 
нетрикутні і навіть неоднорідні поверхневі сітки, для яких немодливо побудувати дискретний оператор Лапласа-Бельтрамі. Ми також показуємо, що метод скінченних елеменітв може бути використаний для розрахунку вузлової сили через поверхневий натяг в нетрикутних елементах поверхні, а середня кривизна і нормальний напрямок можуть бути отримані за допомогою рівняння Лапласа-Янга.

Estimating the normal and curvature for a triangulated surface is necessary for many computations and simulations, such as computer graphics, reverse engineering, medical image analysis, and multiphase flow simulations $[12,11,2,6,13,17]$. Various methods have been proposed and readers can refer to several review articles $[12,16,11]$ and references therein. Among them, Desbrun et al. [4, 9] proposed an approximation method for differential attributes of triangular meshes. Recognizing that the normal vector and mean curvature on a smooth surface can be expressed by the LaplaceBeltrami (LB) operator in differential geometry, the authors integrated the LB operator over a control surface around a vertex of the triangulated mesh for an estimation of the local mean curvature vector. This method has since been employed in various applications, such as computer graphics [1], artificial intelligence [8], and biomedical engineering [18]. In this note, we will present an alternative derivation for the discrete LB operator based on simple physics, namely, the Young-Laplace equation $[6,10]$ and the force balance principle [5]. We will also show that our derived expression is equivalent to the discrete LB method by Desbrun et al. [4, 9].

For a system consisting two static fluids separated by an interface, there may exist a difference in fluid pressure across the interface, and this pressure difference is given by the classical Young-Laplace equation $[20,7,14,10]$ :

$$
P_{\text {in }}-P_{\text {out }}=\gamma\left(\frac{1}{R_{1}}+\frac{1}{R_{2}}\right),
$$

where $\gamma$ is the tension in the interface, $R_{1}$ and $R_{2}$ are the two principal radii of curvature, and $P_{\text {in }}$ and $P_{\text {out }}$, respectively, are the fluid pressures inside and outside of the interface. The normal direction $\mathbf{n}$ of the interface points into the outside fluid (Fig. 1a). The mean curvature $H$ is the mean value of the principle curvatures $\kappa_{1}=1 / R_{1}$ and $\kappa_{2}=1 / R_{2}$, and thus Eq. (1) can be rewritten to

$$
P_{\text {in }}-P_{\text {out }}=2 \gamma H \text {. }
$$

The Young-Laplace equation Eq. (1) can be derived rigorously from physical principles such as the force balance and surface energy minimization [10, 15]. On a differential surface area $\delta A$, over which the surface curvature and normal can be considered constant, the pressure difference $P_{\text {in }}-P_{\text {out }}$ 
(a)

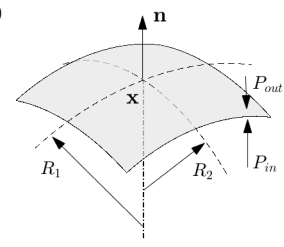

(d)

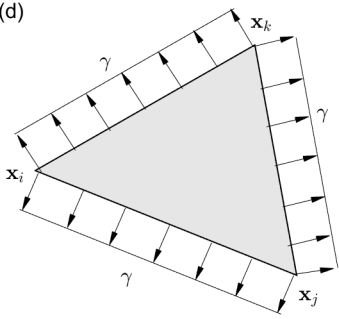

(b)
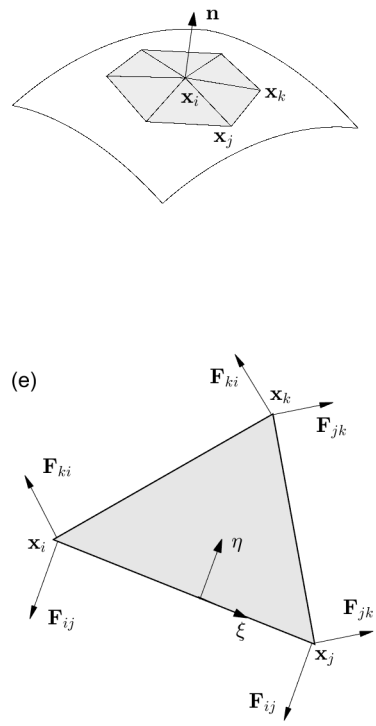

(c)

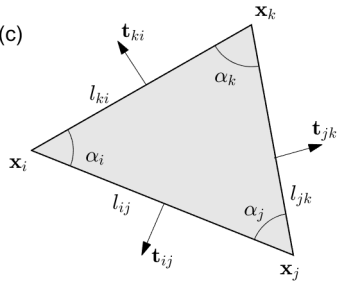

(f)

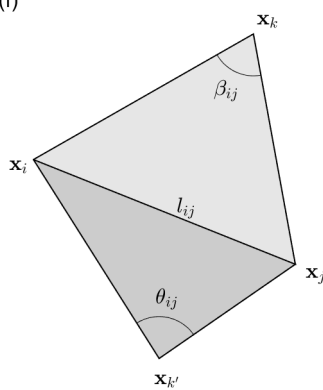

FiguRE 1. Schematic drawings for the method description: (a) the original smooth surface; (b) a vertex $\mathbf{x}_{i}$ and its adjacent elements of the triangulated surface mesh; (c) notations for the interior angles, edge lengths, and outward edge perpendicular vectors of the element $E_{i j k}$; (d) the free-body diagram for the element $E_{i j k}$ with uniform force distributions along edges; (e) the replacement of the uniform force distributions with end forces; and (f) the two side elements $E_{i k^{\prime} j}$ and $E_{i j k}$ sharing the same edge and the two opposite angles $\beta_{i j}$ and $\theta_{i j}$.

generates a force

$$
\delta \mathbf{F}=\left(P_{\text {in }}-P_{\text {out }}\right) \delta A \mathbf{n}=2 \gamma H \delta A \mathbf{n} .
$$

On the other hand, for a surface discretized into triangular elements (Fig. 1b), a nodal force $\mathbf{F}_{i}$ is required on vertex $\mathbf{x}_{i}$ to counter-balance the surface tension effect in triangular elements. We consider one such adjacent element $E_{i j k}$ with vertices $\mathbf{x}_{i}, \mathbf{x}_{j}$ and $\mathbf{x}_{k}$, and denote its interior angles as $\alpha$, edges as $l$, and the outward edge perpendicular vector as $\mathbf{t}$, with corresponding subscripts (Fig. 1c). A free-body diagram is constructed for this element in Fig. 1d. Here uniform force distributions of magnitude $\gamma$ in the outward perpendicular directions are applied along the element 
edges, according to the surface tension definition [10,3]. Take the edge connecting vertices $\mathbf{x}_{i}$ and $\mathbf{x}_{j}$ in Fig. $1 \mathrm{~d}$ as an example. The total surface tension force along this edge is the product of the surface tension (force density) $\gamma$ and the edge length $l_{i j}$, and the force is in the outward direction $\mathbf{t}_{i j}$. We then replace this uniform force distribution with two equal point forces $F_{i j}=\gamma l_{i j} / 2$, [5], at the end points of this edge, Fig. 1e. Similar analysis can be applied to the other two edges, and we have:

$$
F_{i j}=\frac{\gamma l_{i j}}{2}, \quad F_{j k}=\frac{\gamma l_{j k}}{2}, \quad F_{k i}=\frac{\gamma l_{k l}}{2} .
$$

Here and afterwards we use $l$ to represent the segment length between two points indicated by the subscripts. For example, in the above equations, $l_{i j}$, $l_{j k}$, and $l_{k i}$ are the edge lengths of the element $E_{i j k}$. The nodal force $\mathbf{F}_{i, E_{i j k}}$, the force resulted at vertex $\mathbf{x}_{i}$ due to the surface tension $\gamma$ in element $E_{i j k}$, is

$$
\mathbf{F}_{i, E_{i j k}}=F_{k i} \mathbf{t}_{k i}+F_{i j} \mathbf{t}_{i j}
$$

To further simplify this equation, we set the local coordinate system $(\xi, \eta)$ in the plane of the element $E_{i j k}$ as shown in Fig. 1e. The outward directions at the element edges can now be expressed as

$$
\mathbf{t}_{i j}=-\boldsymbol{\eta}, \quad \mathbf{t}_{j k}=\sin \alpha_{j} \boldsymbol{\xi}+\cos \alpha_{j} \boldsymbol{\eta}, \quad \mathbf{t}_{k i}=-\sin \alpha_{i} \boldsymbol{\xi}+\cos \alpha_{i} \boldsymbol{\eta} .
$$

The nodal force in Eq. (2) can then be rewritten as

$$
\begin{aligned}
\mathbf{F}_{i, E_{i j k}}=\frac{\gamma}{2}\left(l_{k i} \mathbf{t}_{k i}+l_{i j} \mathbf{t}_{i j}\right) & =\frac{\gamma}{2}\left[-l_{k i} \sin \alpha_{i} \boldsymbol{\xi}-\left(l_{i j}-l_{k i} \cos \alpha_{i}\right) \boldsymbol{\eta}\right] \\
& =-\frac{\gamma l_{j k}}{2}\left(\sin \alpha_{j} \xi+\cos \alpha_{j} \boldsymbol{\eta}\right)=-\frac{\gamma l_{j k} \mathbf{t}_{j k}}{2},
\end{aligned}
$$

where the following geometric relations for the element triagle $E_{i j k}$ have been utilized: $l_{k i} \sin \alpha_{i}=l_{j k} \sin \alpha_{j}$ (the same altitude to the edge $l_{i j}$ ) and $l_{i j}=l_{k i} \cos \alpha_{i}+l_{j k} \cos \alpha_{j}$ (the edge length $l_{i j}$ is the sum of the preojections of edges $l_{k i}$ and $l_{j k}$ ).

It is interesting to see that the nodal force $\mathbf{F}_{i, E_{i j k}}$ at vortex $\mathbf{x}_{i}$ is simply the force required to counter balance the surface tension force $\gamma l_{j k}$ on the opposite edge. The total force at vortex $\mathbf{x}_{i}$ is simply the sum of such nodal forces from all adjacent elements:

$$
\mathbf{F}_{i}=-\frac{\gamma}{2} \sum_{(j, k)} l_{j k} \mathbf{t}_{j k}
$$

Considering the triangulated mesh in Fig. $1 \mathrm{~b}$ is a discrete approximation of the original smooth surface in Fig. 1a, the nodal force $\mathbf{F}_{i}$ given in Eq. (5) is therefore an approximation of the force $\delta \mathbf{F}$ due to the pressure difference 


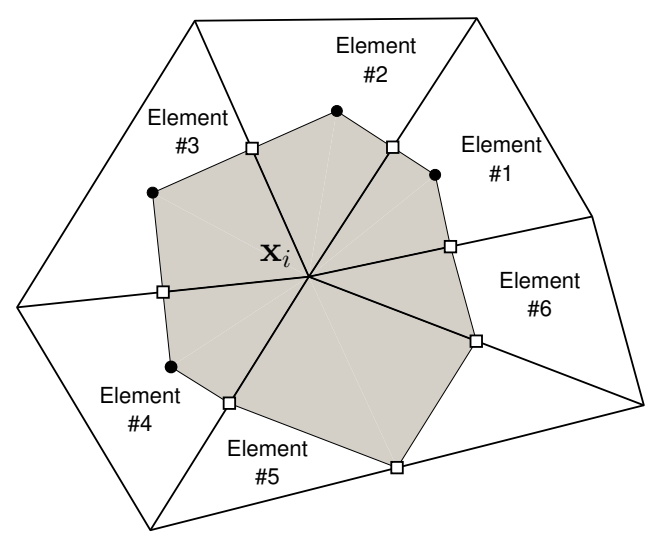

Figure 2. A graphical description of the Voronoi area calculation. The Voronoi area $A_{i}$ for vortex $\mathbf{x}_{i}$ is the sum of the fractional Voronoi area $A^{v}$ of each surrounding elements \#1 \#6 (shaded area), see Eq. (8). For an acute triangle (such as Elements \#1 \#4), the fraction Voronoi area of vertex $\mathbf{x}_{i}$ is the area of the quadrilateral formed by the vortex $\mathbf{x}_{i}$, the midpoints of the two edges from $\mathbf{x}_{i}$ (white squares), and the circumcenter of the triangle (black circles), see Eq. (9). For an obtuse triangle, the circumcenter locates out of the triangle and thus the calculation of $A^{v}$ has been modified, [9]: The obtuse triangle is divided into three parts by the two midsegments through the midpoint of the longest edge. Therefore, the fraction Voronoi area for Element \#5 is the area of the quadrilateral formed by vortex $\mathbf{x}_{i}$ and the three edge midpoints of Element \#5, see Eq. (10); and the fractional Voronoi area for Element $\# 6$ is the area of the triangle formed by vortex $\mathbf{x}_{i}$ and the two midpoints of the edges from $\mathbf{x}_{i}$, see Eq. (11).

over a control volume surface patch $A_{i}$ associated with vortex $\mathbf{x}_{i}$

$$
\mathbf{F}_{i} \approx 2 \gamma H A_{i} \mathbf{n} .
$$

Combining Eqs. (6) and (5) and canceling the surface tension $\gamma$ yield the following approximation for the mean curvature normal $H \mathbf{n}$

$$
(H \mathbf{n})\left(\mathbf{x}_{i}\right) \approx-\frac{1}{4 A_{i}} \sum_{(j, k)} l_{j k} \mathbf{t}_{j k} .
$$


With the nodal coordinates and connectivity available for the mesh network, the opposite edge length $l_{j k}$ and its outward direction $\mathbf{t}_{j k}$ in each adjacent element can be readily calculated. The control volume area $A_{i}$ can be calculated as the modified Voronoi area

$$
A_{i}=\sum_{(j, k)} A_{i j k}^{v}
$$

with the fractional Voronoi $A_{i j k}^{v}$ area given as [9]:

$$
\begin{aligned}
& A_{i j k}^{v}=\frac{\cot \alpha_{j}\left|\mathbf{x}_{k}-\mathbf{x}_{i}\right|^{2}+\cot \alpha_{k}\left|\mathbf{x}_{j}-\mathbf{x}_{i}\right|^{2}}{8}, \quad \max \left(\alpha_{i}, \alpha_{j}, \alpha_{k}\right) \leq \frac{\pi}{2} ; \\
& A_{i j k}^{v}=\frac{A_{i j k}}{2}, \quad \alpha_{i}>\frac{\pi}{2} ; \\
& A_{i j k}^{v}=\frac{A_{i j k}}{4}, \quad \alpha_{j}>\frac{\pi}{2} \quad \text { or } \quad \alpha_{k}>\frac{\pi}{2},
\end{aligned}
$$

where $A_{i j k}$ is the area of element $E_{i j k}$.

(a)

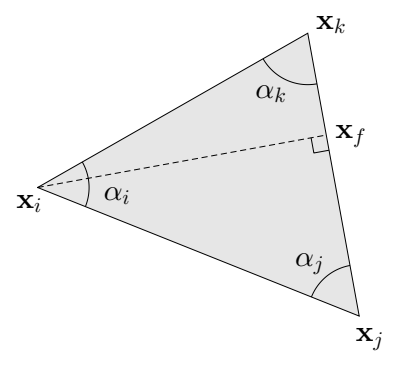

(b)

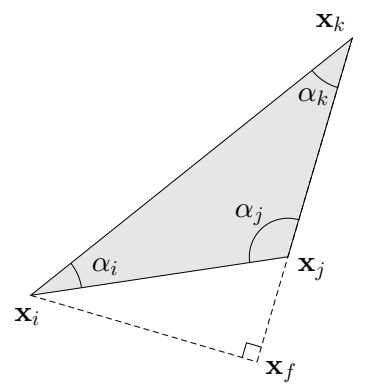

(c)

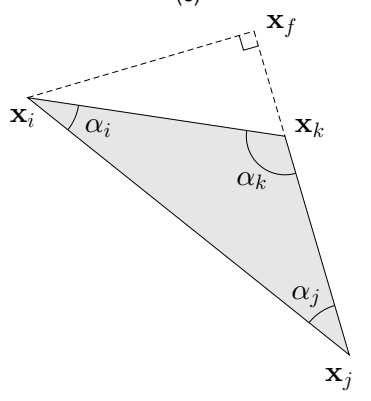

FiguRE 3. The three possible situations for the relative position of altitude foot $\mathbf{x}_{f}$ to the edge ends $\mathbf{x}_{j}$ and $\mathbf{x}_{k}$ : (a) $\mathbf{x}_{f}$ locates between $\mathbf{x}_{j}$ and $\mathbf{x}_{k}$ when $\alpha_{j} \leq \pi / 2$ and $\alpha_{k} \leq \pi / 2$; (b) $\mathbf{x}_{f}$ locates outside of the edge and is closer to $\mathbf{x}_{j}$ when $\alpha_{j}>\pi / 2$; and (c) $\mathbf{x}_{f}$ locates outside of the edge and is closer to $\mathbf{x}_{k}$ when $\alpha_{k}>\pi / 2$.

Please see Fig. 2 for more detailed descriptions of the Voronoi area calculation.

Next, we show that our approximation Eq. (7) actually is equivalent to that given by Desbrun et al. [4, 9]. Again we start with the element $E_{i j k}$ in Fig. 1c, and its inner angles are $\alpha_{i}, \alpha_{j}$, and $\alpha_{k}$ at vortice $\mathbf{x}_{i}, \mathbf{x}_{j}$ and $\mathbf{x}_{k}$, respectively. The position of the foot of altitude $\mathbf{x}_{f}$ on the base $\left|\mathbf{x}_{k}-\mathbf{x}_{j}\right|$ 
can be calculated from $\mathbf{x}_{j}$ and $\mathbf{x}_{k}$ with the distances as weight factors, and the exact relation depends on the relative position of $\mathbf{x}_{f}$ to vortice $\mathbf{x}_{j}$ and $\mathbf{x}_{k}$, see Fig. 3:

$$
\begin{array}{ll}
l_{j k} \mathbf{x}_{f}=l_{k f} \mathbf{x}_{j}+l_{j f} \mathbf{x}_{k}, & \text { for } \alpha_{j} \leq \frac{\pi}{2} \text { and } \alpha_{k} \leq \frac{\pi}{2} ; \\
l_{k f} \mathbf{x}_{j}=l_{j k} \mathbf{x}_{f}+l_{j f} \mathbf{x}_{k}, & \text { for } \alpha_{j}>\frac{\pi}{2} ; \\
l_{j f} \mathbf{x}_{k}=l_{j k} \mathbf{x}_{f}+l_{k f} \mathbf{x}_{j}, & \text { for } \alpha_{k}>\frac{\pi}{2} .
\end{array}
$$

The outward vector $\mathbf{t}_{j k}$, for these three individual situations in Fig. 3 is then expressed respectively as

$$
\begin{aligned}
\mathbf{t}_{j k} & =\frac{\mathbf{x}_{f}-\mathbf{x}_{i}}{l_{i f}}=\frac{l_{k f} \mathbf{x}_{j}+l_{j f} \mathbf{x}_{k}-l_{j k} \mathbf{x}_{i}}{l_{j k} l_{i f}} \\
& =\frac{l_{k f} \mathbf{x}_{j}+l_{j f} \mathbf{x}_{k}-\left(l_{k f}+l_{j f}\right) \mathbf{x}_{i}}{l_{j k} l_{i f}}=\frac{1}{l_{j k}}\left[\frac{l_{k f}}{l_{i f}}\left(\mathbf{x}_{j}-\mathbf{x}_{i}\right)+\frac{l_{j f}}{l_{i f}}\left(\mathbf{x}_{k}-\mathbf{x}_{i}\right)\right] \\
& =\frac{1}{l_{j k}}\left[\cot \alpha_{k}\left(\mathbf{x}_{j}-\mathbf{x}_{i}\right)+\cot \alpha_{j}\left(\mathbf{x}_{k}-\mathbf{x}_{i}\right)\right], \text { for } \alpha_{j} \leq \frac{\pi}{2} \text { and } \alpha_{k} \leq \frac{\pi}{2} ; \\
\mathbf{t}_{j k} & =\frac{\mathbf{x}_{f}-\mathbf{x}_{i}}{l_{i f}}=\frac{l_{k f} \mathbf{x}_{j}-l_{j f} \mathbf{x}_{k}-l_{j k} \mathbf{x}_{i}}{l_{j k} l_{i f}} \\
& =\frac{l_{k f} \mathbf{x}_{j}-l_{j f} \mathbf{x}_{k}-\left(l_{k f}-l_{j f}\right) \mathbf{x}_{i}}{l_{j k} l_{i f}}=\frac{1}{l_{j k}}\left[\frac{l_{k f}}{l_{i f}}\left(\mathbf{x}_{j}-\mathbf{x}_{i}\right)-\frac{l_{j f}}{l_{i f}}\left(\mathbf{x}_{k}-\mathbf{x}_{i}\right)\right] \\
& =\frac{1}{l_{j k}}\left[\cot \alpha_{k}\left(\mathbf{x}_{j}-\mathbf{x}_{i}\right)+\cot \alpha_{j}\left(\mathbf{x}_{k}-\mathbf{x}_{i}\right)\right], \text { for } \alpha_{j}>\frac{\pi}{2} ; \\
\mathbf{t}_{j k} & =\frac{\mathbf{x}_{f}-\mathbf{x}_{i}}{l_{i f}}=\frac{l_{j f} \mathbf{x}_{k}-l_{k f} \mathbf{x}_{j}-l_{j k} \mathbf{x}_{i}}{l_{j k} l_{i f}} \\
& =\frac{l_{j f} \mathbf{x}_{k}-l_{k f} \mathbf{x}_{j}-\left(l_{j f}-l_{k f}\right) \mathbf{x}_{i}}{l_{j k} l_{i f}}=\frac{1}{l_{j k}}\left[-\frac{l_{k f}}{l_{i f}}\left(\mathbf{x}_{j}-\mathbf{x}_{i}\right)+\frac{l_{j f}}{l_{i f}}\left(\mathbf{x}_{k}-\mathbf{x}_{i}\right)\right] \\
& =\frac{1}{l_{j k}}\left[\cot \alpha_{k}\left(\mathbf{x}_{j}-\mathbf{x}_{i}\right)+\cot \alpha_{j}\left(\mathbf{x}_{k}-\mathbf{x}_{i}\right)\right], \text { for } \alpha_{k}>\frac{\pi}{2} .
\end{aligned}
$$


The final expressions for the vector $\mathbf{t}_{j k}$ are identical in all the three situations, and thus we can write the following relation in general:

$$
\mathbf{t}_{j k}=-\frac{1}{l_{j k}}\left[\cot \alpha_{k}\left(\mathbf{x}_{i}-\mathbf{x}_{j}\right)+\cot \alpha_{j}\left(\mathbf{x}_{i}-\mathbf{x}_{k}\right)\right] .
$$

Eq. (7) is then rewritten by enumerating every link instead of every element connected at the same vertex $\mathbf{x}_{i}$ in the summation operation:

$$
H \mathbf{n}\left(\mathbf{x}_{i}\right)=\frac{1}{4 A_{i}}\left[\cot \alpha_{k}\left(\mathbf{x}_{i}-\mathbf{x}_{j}\right)+\cot \alpha_{j}\left(\mathbf{x}_{i}-\mathbf{x}_{k}\right)\right] .
$$

Here $\mathbf{n}\left(\mathbf{x}_{i}\right)$ is the unit normal vector at vertex $\mathbf{x}_{i}$, Fig. 1b. By enumerating each edge from the vertex $\mathbf{x}_{i}$ instead of each element around $\mathbf{x}_{i}$, Eq. (12) can be rewritten to

$$
H \mathbf{n}\left(\mathbf{x}_{i}\right) \approx \frac{1}{4 A_{i}} \sum_{j}\left(\cot \beta_{i j}+\cot \theta_{i j}\right)\left(\mathbf{x}_{i}-\mathbf{x}_{j}\right),
$$

where $\beta_{i j}$ and $\theta_{i j}$ are the opposite angles of the two elements sharing the edge $l_{i j}$, Fig. 1f. This is exactly the same expression given by Desbrun et al. $[4,9]$. We do not present any numerical examples for our method Eq. (7) due to the mathematical identity to Eq. (13), which has been tested in numerous studies $[4,9,1,8,18]$.

In summary, we have derived an estimation expression for the mean curvature vector at vertices of triangulated surfaces, and shown that our expression is equivalent to the result from the discrete LB operator approach by Desbrun et al. [4, 9]. The key idea of our method can also be extended to other non-triangular and even heterogeneous surface meshes. In such situations, instead of Eq. (4), the finite element method [19] can be utilized to calculate the nodal force due to the surface tension effect in each non-triangular surface element.

\section{ACKNOWLEDGMENT}

This work was supported by the Natural Science and Engineering Research Council of Canada (NSERC).

\section{REFERENCES}

[1] B. Bickel, M. Botsch, R. Angst, W. Matusik, M. Otaduy, H. Pfister, M. Gross. Multiscale capture of facial geometry and motion. ACM Transactions on Graphics, 26:33-41, 2007.

[2] S. R. Campbell, R. M. Summers. Analysis of kernel method for surface curvature estimation. International Congress Series, 1268:999-1003, 2004.

[3] Y. A. Cengel, J. M. Cimbala. Fluid Mechanics Fundamentals and Applications. McGraw-Hill, 2014. 
[4] M. Desbrun, M. Meyer, P. Schroder, A. H. Barr. Implicit fairing of irregular meshes using diffusion and curvature flow. In Computer Graphics, pages 317-324. 1999. doi: $10.1145 / 311535.311576$.

[5] E. Hibbeler. Engineering Mechanics: Statics. Pearson, 2016.

[6] P. J. A. Janssen, P. D. Anderson. Boundary-integral method for drop deformation between parallel plates. Physics of Fluids, 19:043602, 2007.

[7] T. Laplace. Supplement au dixieme livre du Traite de Mécanique Céleste, volume 4, pages 1-79. Courcier, Paris, France, 1805.

[8] H. Lombaert, I. Grady, J. R. Polimeni, P. Cheriet. FOCUSR: Feature oriented correspondence using spectral regularization-a method for precise surface matching. IEEE Transactions of Pattern Analysis and Machine Intelligence, 35:2143-2160, 2013. doi: 10.1109/TPAMI.2012.276, url: profs .etsmtl.ca/hlombaert/PAMI-FOCUSR.pdf.

[9] N. Meyer, M. Desbrun, P. Schroderand A. H. Barr. Discrete differential-geometry operators for triangulated 2-manifolds. In H. C. Hege, K. Polthier, editors, Visualization and Meathematics, volume 3, pages 35-57. 2003. doi: 10.1007/978-3-662-05105-4_2.

[10] A. W. Neumann, R. David, Y. Zou. Applied Surface Thermodynamics. CRC Press, Boca Raton, US, 2010.

[11] S. Nigam, V. Agrawal. A review: Curvature approximation on triangular meshes. International Journal of Engineering Science and Innovative Technology, 2:330-339, 2013.

[12] P. Petitjean. A survey of methods for recovering quadrics in triangle meshes. $A C M$ Computing Surveys, 2:1-61, 2002.

[13] S. Popinet. Numerical models of surface tension. Annual Review of Fluid Mechanics, 50:49-75, 2018.

[14] D. A. Rubenstein, W. Yin, M. D. Frame. Biofluid Mechanics. Elsevier, Oxford, UK, 2012. pp: $230-244$.

[15] L. M. Siqveland, L. M. Skjaeveland. Derivations of the Young-Laplace equation. doi: 10.13140/RG.2.1.4485.5768, 2014.

[16] T. Surazhsky, E. Magid, O. Soldea, G. Elber, E. Rivlin. A comparison of gaussian and mean curvatures estimation methods on triangular meshes. In Proceedings of the International Conference on Robotics and Automation, volume 1, pages 1021-1026. Taipei, Taiwan, 2003. doi: 10.1109/ROBOT.2003.1241726, url: ieeexplore.ieee. org/document/1241726.

[17] R. Wang. Nanoparticles influence droplet formation in a T-shaped microfluidic. Journal of Nanoparticle Research, 15:2128, 2013.

[18] D. J. Watson, I. Sazonov, D. C. Zawieja, J. E. Moore, R. van Loon. Integrated geometric and mechanical analysis of an image-based lymphatic valve. Journal of Biomechanics, 64:172-179, 2017. doi: 10.1016/j.jbiomech.2017.09.040, url: www. sciencedirect.com/science/article/pii/S0021929017305134?via\%3Dihub.

[19] J. Whiteley. Finite Element Methods: A Practical Guide. Springer Nature, Cham, Switzerland, 2017. pp: 161-173, url: www.springer.com/gp/book/9783319499703.

[20] T. Young. An essay on the cohesion of fluids. Philosophical Transactions of the Royal Society of London, 95:65-87, 1805.

Received: February 9, 2019, accepted: June 10, 2019.

Sudip Kumar Das

Bharti School of Engineering, Laurentian University, 935 Ramsey Lake Road, Sudbury, Ontario, P3E 2C6, Canada 
Email: sudipkd13@gmail.com

Mirza Cenanovic

Department of Mechanical Engineering, Jonkoping University, SE-55111 JonkopIng, Sweden

Email: Mirza.Cenanovic@ju.se

Junfeng Zhang

Bharti School of Engineering, Laurentian University, 935 Ramsey Lake Road, Sudbury, Ontario, P3E 2C6, Canada

Email: jzhang@laurentian.ca 